\title{
Impact of polydextrose on the faecal microbiota: a double-blind, crossover, placebo-controlled feeding study in healthy human subjects
}

\author{
Adele Costabile ${ }^{1} \dagger$, Francesca Fava ${ }^{1,4} \dagger$, Henna Röytiö ${ }^{2}$, Sofia D. Forssten ${ }^{2}$, Kaisa Olli $^{2}$, Judith Klievink ${ }^{3}$, \\ Ian R. Rowland ${ }^{1}$, Arthur C. Ouwehand ${ }^{2}$, Robert A. Rastall ${ }^{1}$, Glenn R. Gibson ${ }^{1}$ and Gemma E. Walton ${ }^{1 *}$ \\ ${ }^{1}$ Department of Food and Nutritional Sciences, University of Reading, Reading RG6 6AP, UK \\ ${ }^{2}$ Danisco Health and Nutrition, Sokeritehtaantie 20, O2460 Kantvik, Finland \\ ${ }^{3}$ Wageningen University, Wageningen, The Netherlands \\ ${ }^{4}$ Nutrition and Nutrigenomics, Food Quality and Nutrition Department, IASMA Research and Innovation Centre, \\ Fondazione Edmund Mach, Istituto Agrario di San Michele all'Adige, Via Mach 1, San Michele all'Adige 38010 (TN), Italy
}

(Submitted 19 May 2011 - Final revision received 26 September 2011 - Accepted 27 September 2011 - First published online 21 November 2011)

\section{Abstract}

In this placebo-controlled, double-blind, crossover human feeding study, the effects of polydextrose (PDX; $8 \mathrm{~g} / \mathrm{d}$ ) on the colonic microbial composition, immune parameters, bowel habits and quality of life were investigated. PDX is a complex glucose oligomer used as a sugar replacer. The main goal of the present study was to identify the microbial groups affected by PDX fermentation in the colon. PDX was shown to significantly increase the known butyrate producer Ruminococcus intestinalis and bacteria of the Clostridium clusters I, II and IV. Of the other microbial groups investigated, decreases in the faecal Lactobacillus-Enterococcus group were demonstrated. Denaturing gel gradient electrophoresis analysis showed that bacterial profiles between PDX and placebo treatments were significantly different. PDX was shown to be slowly degraded in the colon, and the fermentation significantly reduced the genotoxicity of the faecal water. PDX also affected bowel habits of the subjects, as less abdominal discomfort was recorded and there was a trend for less hard and more formed stools during PDX consumption. Furthermore, reduced snacking was observed upon PDX consumption. This study demonstrated the impact of PDX on the colonic microbiota and showed some potential for reducing the risk factors that may be associated with colon cancer initiation.

\section{Key words: Polydextrose: Human faecal microbiota: Genotoxicity: Biomarkers of colonic health}

Prebiotics are growing in popularity amid evidence of a host of beneficial effects, including enhancing immune function ${ }^{(1)}$ and improving mucosal structural ${ }^{(2)}$ and cellular turnover ${ }^{(3)}$. Some studies even indicate anti-cancer potential ${ }^{(4)}$ to be one among the many beneficial effects. A prebiotic is a selectively fermented ingredient that results in specific changes in the composition and/or activity of the gastrointestinal microbiota, thus conferring benefit(s) upon host health ${ }^{(5)}$. To date, much of the work on prebiotics has focused on fructo-oligosaccharides, inulin and galacto-oligosaccharides ${ }^{(6)}$. As the commercial interest in functional food ingredients and colonic health has grown worldwide, further prebiotics may eventually make their way into the market. However, the ultimate tests for prebiotic activity, the human volunteer trials, are scarce or lacking for the majority of these candidates ${ }^{(7)}$. Thus, more evidence on their efficacy is needed for a prebiotic status to be achieved.
A diet that contains sufficient fibre is likely to be advantageous for consumer health. Epidemiological studies have long suggested an inverse association between dietary fibre intake and a range of colonic and systemic human diseases including certain cancers and $\mathrm{CVD}^{(8)}$. The increased availability of carbohydrate within, especially, the distal part of the intestine means increased microbial saccharolytic activities and SCFA production. This leads to a potential reduction of proteolytic activities that are linked to carcinogen or genotoxin production ${ }^{(9)}$. In addition to decreased proteolytic activity, the independent role of increased SCFA concentrations, especially butyrate, has been speculated to be behind some of the beneficial effects associated with fibre ${ }^{(10)}$. Low- or non-fermentable fibres, such as cellulose, may act as bulking agents, improve intestinal transit time and, thereby, reduce the exposure of human mucosal tissue

\footnotetext{
Abbreviations: COX, cyclo-oxygenase; DGGE, denaturing gel gradient electrophoresis; FISH, fluorescence in situ hybridisation; PDX, polydextrose; qPCR, quantitative PCR.
}

*Corresponding author: G. E. Walton, email g.e.walton@reading.ac.uk

† These authors contributed equally to this work. 
to genotoxic and carcinogenic compounds ${ }^{(11)}$. A prebiotic, on the other hand, has an additional property in that it selectively alters the intestinal microbiota, modulating the composition and/or activity to increase the relative population levels of potentially beneficial organisms, such as bifidobacteria ${ }^{(5)}$.

Polydextrose (PDX) is a soluble fibre synthesised from glucose; it is frequently used to increase the fibre content of food. PDX has a highly branched structure with a spectrum of glycosidic linkages ${ }^{(12)}$. Previous in vitro research has shown that PDX is selectively fermented by the faecal microbiota, to stimulate bifidobacterial growth ${ }^{(13)}$. These findings are supported by a feeding trial where dose-dependent increases in bifidobacteria and lactobacilli and decreases of three species of bacteroides were observed ${ }^{(14)}$. However, it is worth noting that in the feeding trial of Jie et al. ${ }^{(15)}$, enumeration is done using selective plating techniques, though such enumeration techniques are problematic ${ }^{(16)}$. In vitro studies suggest that PDX may have protective activities for markers of colorectal cancer; for example, cyclo-oxygenase (COX)-2 expression has been observed to be elevated in individuals with colon cancer $^{(17)}$, and fermentation products derived from PDX have been demonstrated to lower the expression of COX-2 in vitro by Caco- 2 cells ${ }^{(18)}$. In addition, similar results were obtained in animal studies with reduced intestinal levels of branched chain fatty acids and biogenic amines ${ }^{(19,20)}$. Furthermore, in pigs, PDX tended to decrease the expression of mucosal COX-2, therefore possibly reducing the risk of developing colon cancer-promoting conditions in the distal intestine ${ }^{(20)}$. Furthermore, Peuranen et al. ${ }^{(20)}$ reported an immune-stimulatory effect in the intestine by PDX with an associated change in the microbial metabolism, including butyrate production and reduction in putrefaction. Tools for the measurement of colon cancer risk factors are limited in short-term intervention studies. However, the use of single cell genotoxicity screening, or the comet assay, is gaining interest as a straightforward method for examining DNA damage and is, therefore, being considered as a biomarker for monitoring the effects of dietary intervention on cancer risk ${ }^{(21)}$. Furthermore, human intervention studies have shown that PDX may also provide benefits to colonic function ${ }^{(22)}$.

The impact of PDX on the human colonic microbiota has been investigated to some extent, but would require further substantiation on the effects, in particular, on recognised beneficial bacteria, such as bifidobacteria and lactobacilli. To this end, a placebo-controlled, double-blind human feeding study was conducted on thirty-one healthy adult volunteers in a crossover manner. Changes in the colonic microbiota were determined by measuring bacterial population levels using fluorescence in situ hybridisation (FISH) and quantitative PCR (qPCR). In addition, a detailed qualitative study of the total microbiota diversity was performed on total faecal DNA extracts via denaturing gel gradient electrophoresis (DGGE). Faecal concentrations of SCFA were also determined; furthermore, gastrointestinal symptoms and stool characteristics were recorded (stool frequency, consistency, abdominal pain, intestinal bloating and flatulence) in order to assess tolerance. Additionally, markers of immune function and changes in the genotoxic nature of the faecal water and COX induction of the colon cells were assessed to determine whether the intervention would offer potential benefits against markers of colon cancer risk.

\section{Experimental methods}

\section{Subjects}

A total of thirty-three healthy volunteers (18-50 years of age) were enrolled from the Reading area; two volunteers dropped out due to personal reasons before the start of the intervention ( $n$ 31). Written informed consent was obtained from all participants and the study protocol was conducted according to the guidelines laid down in the Declaration of Helsinki and all procedures involving human subjects were approved by the Ethics and Research Committee of the University of Reading. Written informed consent was obtained from all subjects. Inclusion criteria for participation in the study were: a signed consent form, age 18-50 years inclusive, BMI $19-25 \mathrm{~kg} / \mathrm{m}^{2}$ inclusive and good general health. Volunteers with evidence of physical/mental disease, major surgery, history of drug abuse, severe allergy, a history of severe abnormal drug reaction and smokers were excluded. Volunteers were also excluded if pregnant, lactating or planning pregnancy. Intake of an experimental drug within 4 weeks before study, former participation in prebiotic, probiotic or laxative trials within 3 months, or use of antibiotics within 6 months before the study, chronic constipation, diarrhoea or other chronic gastrointestinal complaints (e.g. irritable bowel syndrome) were all exclusion criteria. Any intake of prebiotics, probiotics (live yoghurts, fermented milk drinks) and drugs active on gastrointestinal motility, antibiotic treatment or any class of laxative was not permitted. All medication taken throughout the duration of the study was recorded in diaries. Volunteers were instructed not to alter their usual diet or fluid intake during the trial.

\section{Study design}

The dietary intervention study was performed in a doubleblind, randomised, placebo-controlled crossover manner. For a period of $14 \mathrm{~d}$ before the dietary intervention study, volunteers followed a restricted diet, refraining from consumption of yoghurts, prebiotic supplements and probiotics. A total of thirty-one subjects were randomly allocated into one of two groups. For volunteer randomisation, baseline bifidobacteria levels were enumerated and volunteers were allocated into the two groups in such a way that the two groups did not significantly differ for baseline bifidobacteria numbers.

The first group ( $n$ 16) consumed PDX powder (Litesse ${ }^{\circledR}$ Ultra, $8 \mathrm{~g} / \mathrm{d}$; Danisco UK, Redhill, UK) for 3 weeks, and then after a 3-week washout period, they consumed the equivalent placebo (maltodextrin powder, 8g/d, Syral, Marckolsheim, France) for 3 weeks. The second group ( $n$ 15) received first the placebo for 3 weeks, and then after a 3 -week washout period, PDX powder for another 3 -week treatment period. During the 3-week washout period, no trial product was consumed.

All test products were packaged, labelled and randomised by Danisco before the study. The study was blinded to 
investigators and volunteers. Volunteers were asked to keep diaries throughout the study to record stool frequency, consistency (constipation, hard, formed, or soft stool or diarrhoea), abdominal pain (none, mild, moderate or severe), intestinal bloating (none, mild, moderate or severe) and flatulence (none, mild, moderate or severe) on a daily basis. Any concomitant medication or adverse events were also recorded. Faecal samples were collected from each volunteer at five different time points, before and after each treatment: at baseline (before PDX intake, pre-PDX), following PDX intake, following washout 1 (post-PDX and before maltodextrin, pre-maltodextrin), following maltodextrin intake and following washout 2 (post-maltodextrin).

\section{Quality of life questionnaires}

Volunteers were issued quality of life questionnaires to complete at the end of the treatment periods $4 \mathrm{~h}$ following consumption of the test product. This questionnaire was to rate hunger, motivation, mood and mental alertness by marking along a line between 'not at all' and 'very'. The position along the line was quantified using a ruler to give rise to a value of between 1 and 10. These were used to assess general feeling of the volunteers following the treatments.

\section{Collection and stool sample preparation}

Freshly voided faecal samples were stored in an anaerobic cabinet $\left(10 \% \mathrm{H}_{2} ; 10 \% \mathrm{CO}_{2} ; 80 \% \mathrm{~N}_{2}\right.$; Don Whitley Scientific, Shipley, UK) for no longer than $2 \mathrm{~h}$ before processing.

For FISH and SCFA analysis, samples were diluted 1 in 10 $(\mathrm{w} / \mathrm{w})$ with PBS $(0 \cdot 1 \mathrm{M} ; \mathrm{pH} 7 \cdot 0)$ and mixed in a Stomacher 400 (Seward, Norfolk, UK) for $2 \mathrm{~min}$ at normal speed (460 paddle beats per min). Of the faecal slurries, $5 \mathrm{ml}$ were transferred into $50 \mathrm{ml}$ sterile plastic centrifuge tubes containing $2 \mathrm{~g}$ of glass beads (diameter $=5 \mathrm{~mm}$ ) and vortexed for $30 \mathrm{~s}$ to further homogenise the samples.

\section{Enumeration of faecal bacterial populations by fluorescence in situ hybridisation}

FISH was performed as described previously ${ }^{(())}$. All oligonucleotide probes were Cy3-labelled and synthesised by
Sigma-Aldrich (Poole, UK). Table 1 gives the details of probes used in this study.

\section{DNA extraction for denaturing gel gradient electrophoresis}

For the isolation of bacterial DNA, $2 \mathrm{~g}$ of frozen faecal samples $\left(-70^{\circ} \mathrm{C}\right.$ in $7 \mathrm{ml}$ sterile Sterlin tubes) were used. The samples were thawed at room temperature and extraction of bacterial DNA was carried out using QIAamp DNA Stool Mini Kit (QIAGEN Limited, Crawley, UK), essentially following the manufacturer's instructions. The protocol was modified by an initial disruption step using glass beads (diameter $0 \cdot 1 \mathrm{~mm}$ ) and a FastPrep beadbeater (Bio101 Savant FastPrep FP120, FastPrep ${ }^{\circledR}$ Instrument, Qbiogene, Cambridge, UK) set at speed 6 for two runs of $40 \mathrm{~s}$. DNA quality was checked by running $5 \mu \mathrm{l}$ aliquots of the samples on $0.8 \%(\mathrm{w} / \mathrm{v})$ ultraPURE agarose (Gibco-BRL, Paisley, UK) gels containing ethidium bromide $(0.4 \mathrm{mg} / \mathrm{ml})$, and visualising the bands using UV light. The quantity of DNA in each sample was determined using a NanoDrop ND-1000 Spectrophotometer (NanoDrop Technologies, Wilmington, DE, USA). Samples were stored at $-20^{\circ} \mathrm{C}$.

\section{Denaturing gradient gel electrophoresis}

Fragments $(230 \mathrm{bp}$ ) derived from the variable $\mathrm{V} 3$ region of the 16S rRNA gene were amplified using the universal primers P2 and $\mathrm{P} 3^{(23)}$. Primers were synthesised by Sigma-Genosys (Haverhill, UK). DGGE was carried out as described previously $^{(24)}$. The V20-HCDC DGGE system (BDH, Poole, UK) was used with gels comprising 35-60\% gradients and run at $100 \mathrm{~V}$. Gels were silver-stained according to the previously published method ${ }^{(24)}$

The gel pictures were analysed by the Gel Compar II software (Applied Maths NV, Sint-Martens-Latem, Belgium). Following normalisation, bands were defined for each sample using the appropriate densitometric curves. Bands constituting less than $1 \%$ of the total band area were omitted from further analysis. Similarity between DGGE profiles was determined by calculating the Pearson's correlation. Clustering of the sample profiles was done using the unweighted pair-group method using arithmetic average with a tolerance of $5 \%$.

Shannon-Weaver index, Simpson's index and Fisher's index were calculated using an implementation on Gel Compare II

Table 1. Probes used in this study for fluorescence in situ hybridisation analysis

\begin{tabular}{|c|c|c|c|}
\hline Target* $^{*}$ & Probe sequence $\left(5^{\prime}-3^{\prime}\right)$ & Accession no. & $\begin{array}{c}\text { Hybridisation - washing } \\
\text { temperature }\left({ }^{\circ} \mathrm{C}\right)\end{array}$ \\
\hline Erec482 & GCT TCT TAG TCA RGT ACC G & pB-00963 & 50 \\
\hline Bac303 & CCA ATG TGG GGG ACC TT & pB-00031 & 45 \\
\hline Fpra655 & CGC CTA CCT CTG CAC TAC & pB-00734 & 58 \\
\hline Bif164 & CAT CCG GCA TTA CCA CCC & pB-00037 & 50 \\
\hline Ato291 & GGT CGG TCT CTC AAC CC & pB-00943 & 50 \\
\hline Lab158 & GGT ATT AGC AYC TGT TTC CA & ND† & 45 \\
\hline Chis 150 & TTA TGC GGT ATT AAT CTY CCT TT & pB-00962 & 50 \\
\hline
\end{tabular}


software (Applied Maths NV, Sint Martens-Latem, Belgium). They were used to compare changes in the diversity of microbial communities within treatments and baseline. Shannon-Weaver index $\left(H^{\prime}\right)$, Simpson's index $(D)$ and Fisher's alpha index $(\alpha)$ were calculated as done previously ${ }^{(24)}$.

\section{DNA extraction for quantitative $P C R$}

Microbial DNA was extracted from the faecal samples by an initial bead beating step of two $3 \times 30 \mathrm{~s}$ cycles at $6800 \mathrm{rpm}$, and thereafter with the use of a modified Promega Wizard genomic DNA purification kit (Promega, Madison, WI, USA). DNA isolation was performed according to instructions of the manufacturer. DNA concentrations were measured by a NanoDrop ND-1000 Spectrophotometer (NanoDrop Technologies, Wilmington, DE, USA) and samples were stored at $-20^{\circ} \mathrm{C}$ until qPCR analyses.

\section{Quantitative PCR}

Extracted microbial DNA (1 ng) was analysed by qPCR, using primers specific for Atopobium spp., Clostridium difficile, C. leptum group (Clostridium cluster IV), C. bistolyticum (clusters I and II), C. perfringens, Desulfovibrio intestinalis, Roseburia intestinalis and Staphylococcus aureus (Table $2^{(25-30)}$ ). Each sample was analysed in triplicate and all samples of one subject analysed in the same run. No template controls and DNA standards from bacterial strains were included on each plate to enable quantification of the bacterial content of the samples.

\section{SCFA analysis by GC}

SCFA concentrations were analysed by a method adapted from Zhao et $a l .{ }^{(31)}$, as described by Walton et al. ${ }^{(32)}$. Peaks were integrated using Atlas Lab managing software (Thermo Lab Systems, Mainz, Germany). Fatty acid concentrations were calculated by comparing their peak areas with those of the standards and were expressed as $\mathrm{mmol} / \mathrm{g}$ faeces.

\section{Immunological analyses}

Concentrations of IgA and $\mathrm{PGE}_{2}$ were measured from the soluble fraction of the faeces. The frozen samples were thawed and extracted with bovine serum albumin as described previously ${ }^{(20)}$ and stored at $-20^{\circ} \mathrm{C}$ before analysis.
Concentrations of $\mathrm{IgA}$ and $\mathrm{PGE}_{2}$ were determined using ELISA according to the respective manufacturer's instructions (E80-102; Bethyl Laboratories, Inc., Montgomery, TX, USA; Cayman Chemical Company Limited, Ann Arbor, MI, USA) and the results were expressed as $\mathrm{mg}$ or $\mathrm{pg} / \mathrm{g}$ faeces (fresh weight), respectively.

\section{Faecal water preparation}

Faecal samples were diluted 1:1 (w/v) in 1 $\mathrm{m}$-ice-cold PBS in a stomacher bag. Samples were homogenised in a stomacher for $2 \mathrm{~min}$ at high speed or until a uniform consistency was achieved. For each sample, $10 \mathrm{ml}$ aliquots, in duplicate, were then transferred into ultracentrifuge tubes (Beckman Ultra-clear tubes; Beckman Limited, High Wycombe, UK) and the tubes stored at $-70^{\circ} \mathrm{C}$. Samples were thawed on ice before centrifugation, then ultracentrifuged at $64000 \mathrm{~g}$ for $2 \mathrm{~h}$ at $4^{\circ} \mathrm{C}$ (Beckman Optima L90K Ultracentrifuge; Beckman Limited, High Wycombe, UK). Following centrifugation, the tubes were placed on ice and supernatants (faecal water) carefully removed and placed into sterile $7 \mathrm{ml}$ Sterilin tubes. The faecal waters were then filtered through $0.2 \mu \mathrm{m}$ syringe filter, dispensed into $0.5 \mathrm{ml}$ aliquots and frozen at $-70^{\circ} \mathrm{C}$ until analysis.

\section{Determination of DNA damage by single cell gel electrophoresis (comet assay)}

The comet assay (single cell gel electrophoresis) was used to microscopically detect DNA damage at the level of a single cell as described earlier ${ }^{(33)}$. The assay was conducted on the baseline faecal water sample for all volunteers. The nine volunteers whose baseline samples caused high-medium levels of DNA damage to the HT29 cells and two additional low-level faecal waters were investigated for the remaining time-points. Briefly, after $48 \mathrm{~h}$ of cultivation in Dulbecco's modified Eagle's medium supplemented with 10\% (w/v) fetal bovine serum and penicillin $(50,000 \mathrm{U} / \mathrm{L})$ streptomycin $(50 \mu \mathrm{g} / \mathrm{ml})$ at $37^{\circ} \mathrm{C}$ in air with $5 \% \mathrm{CO}_{2}$, sub-confluent cultures of HT29 were harvested by trypsination and adjusted to a concentration of $2 \times 10^{6}$ cells $/ \mathrm{ml}$ in serum-free Dulbecco's modified Eagle's medium. Duplicate tubes containing $100 \mu \mathrm{l}$ of cell suspension and $100 \mu$ l of the respective faecal waters or PBS (negative controls) were incubated at $37^{\circ} \mathrm{C}$ for $30 \mathrm{~min}$ with constant gentle shaking. After incubation, one series of

Table 2. Primers used in the quantitative PCR to enumerate the microbial groups of interest

\begin{tabular}{|c|c|c|c|}
\hline Species & Primer name & $\begin{array}{c}\text { Annealing } \\
\text { temperature }\left({ }^{\circ} \mathrm{C}\right)\end{array}$ & References \\
\hline Atopobium group & gAtop_F gAtop_R & 58 & Rinttilä et al. ${ }^{(25)}$ \\
\hline Clostridium difficile & cdif_F2 cdif_R2 & 60 & Lahtinen et al. ${ }^{(26)}$ \\
\hline $\begin{array}{l}\text { Clostridium leptum subgroup } \\
\text { (cluster IV) }\end{array}$ & sg_Clep_Fsg_Clep_R3 & 62 & Matsuki et al. ${ }^{(27)}$ \\
\hline Clostridium perfringens & CPTAFW CPTARV & 55 & Tiihonen et al. ${ }^{(28)}$ \\
\hline Clostridium clusters I and II & g_Cperf_F g_Cperf_R & 55 & Rinttilä et al. ${ }^{(25)}$ \\
\hline Desulfovibrio intestinalis & apsA1F apsA1R & 62 & Tiihonen et al. ${ }^{(28)}$ \\
\hline Roseburia spp. & Roseint_F gRose_R & 56 & Mäkivuokko et al. ${ }^{(29)}$ \\
\hline Staphylococcus aureus & NUC1 NUC2 & 60 & Brakstad et al. ${ }^{(30)}$ \\
\hline
\end{tabular}


tubes was treated with $75 \mu \mathrm{m}-\mathrm{H}_{2} \mathrm{O}_{2}$ as a genotoxic model agent for $5 \mathrm{~min}$ on ice. Samples were centrifuged at $280 \boldsymbol{g}$ for $5 \mathrm{~min}$ at $4^{\circ} \mathrm{C}$ and washed once with PBS. Following this, three $50 \mu \mathrm{l}$ aliquots of each sample were centrifuged again and the resulting cell pellets re-suspended in warm, low melting point agarose and further processed as described ${ }^{(33)}$. Cell numbers and viability of HT29 were assessed before and after incubation using Trypan Blue exclusion assay.

\section{Cyclo-oxygenase gene expression}

Human colon-derived carcinoma cells, Caco-2 (ATCC HTB37), were used to study the effects of faecal water samples on the COX gene expression of colonic epithelial cells. The Caco- 2 cells were maintained at $37^{\circ} \mathrm{C}$ in a humidified air $/ 5 \%$ $\mathrm{CO}_{2}$ atmosphere in basal culture of Dulbecco's modified Eagle's medium (Invitrogen, Carlsbad, CA, USA) supplemented with $10 \%$ fetal bovine serum (Invitrogen), $2 \mathrm{mmol} / \mathrm{l}$ stable glutamine (Invitrogen), $1 \times$ non-essential amino acids (Invitrogen), $20 \mathrm{U} / \mathrm{ml}$ penicillin (Invitrogen), $20 \mu \mathrm{g} / \mathrm{ml}$ streptomycin (Invitrogen) and $0.5 \mu \mathrm{g} / \mathrm{ml}$ amphotericin (Invitrogen). The cells were seeded as $6.4 \times 10^{4}$ cells $/ \mathrm{cm}^{2}$ on twelve-well cell culture plates (Greiner Bio-One $\mathrm{GmbH}$ ). On the second day following seeding, the medium was replaced with the serum- and antibiotic-free culture medium. On the third day of culture, the Caco-2 cells were treated with $0.5 \%(\mathrm{w} / \mathrm{v})$ faecal water samples prepared in the serum- and antibioticfree culture medium. In addition to the medium-only control, $5 \mathrm{mmol} / \mathrm{l}$ sodium butyrate (Sigma-Aldrich, Chemie GmbH, Steinheim, Germany) and $100 \mathrm{mmol} / 1 \mathrm{NaCl}$ (J.T. Baker, Deventer, The Netherlands) were used as positive and negative controls, respectively. The cells were incubated at $37^{\circ} \mathrm{C}$ in a humidified air $/ 5 \% \mathrm{CO}_{2}$ atmosphere for $20 \mathrm{~h}$, after which the cells were lysed in $300 \mu \mathrm{l}$ RA1 Lysis Buffer (MachereyNagel, Düren, Germany) containing $1 \% \beta$-mercaptoethanol (Sigma-Aldrich).

Total RNA was isolated from the lysed cell samples using a nucleic acid extraction robot (Corbett, Sydney, Australia), quantified with NanoDrop ND-1000 (NanoDrop Technologies; Thermo Fisher Scientific, Wilmington, DE, USA) and subjected to complementary DNA synthesis. Reverse transcription was conducted according to the manufacturer's instructions by using SuperScript III (Invitrogen) and random primers (Invitrogen). The concomitant COX-1 and COX-2 gene expression analyses were done with real-time qPCR using specific TaqMan ${ }^{\circledR}$ Gene Expression Assays (Applied Biosystems, Foster City, CA, USA). All assays were run with 7500 FAST Real-Time PCR System (Applied Biosystems). PCR results were analysed with the relative quantification method ${ }^{(34)}$ describing the change in expression of the target gene in relation to a reference, which was the medium-only control. The amount of the target gene was also normalised to an internal control gene, a ribosomal large protein (RPLP0) ${ }^{(34)}$.

\section{Polydextrose measurements}

The amounts of PDX excreted in the faeces were measured using the HPLC method as described previously ${ }^{(12)}$.

\section{Statistical analysis}

The data from the crossover study were analysed with linear mixed-effects models in a repeated-measures manner assuming no carry-over effect, having a random effect for the subject accounting for repeated measures, and fixed effects for the order of treatments (first PDX, second placebo or vice versa) and for the treatment (placebo, PDX, washout or baseline), and finally having a baseline regression coefficient accounting for individual baseline differences between the subjects. Based on the residual analysis, some of the original variables were logtransformed. The linear model analyses were conducted with statistical programming language $\mathrm{R}$ (version 2.11.1; R-Core, Auckland, New Zealand) using the non-linear mixed-effects package (version 3.1-97; R-Core, Auckland, New Zealand).

Data for DGGE indices were analysed by using one-way ANOVA and paired Student's $t$ test using GraphPad Prism 5.0 (GraphPad Software, La Jolla, CA, USA).

\section{Results}

Overall, thirty-three participants entered into this crossover study (sixteen female, seventeen male), two dropped out (both male) - due to moving from the local area. Therefore, a total of thirty-one volunteers (sixteen female, fifteen male) aged 22-52 years (average age 33 years) with an average BMI of $24 \cdot 1(\mathrm{SD} 2 \cdot 8) \mathrm{kg} / \mathrm{m}^{2}$ completed the study.

\section{Faecal microbiota}

A primary objective of the study was to assess the impact of PDX on the intestinal microbiota. 16S rRNA-based FISH probes were used to target predominantly significant groups of human faecal bacteria (Table 1). Bacterial numbers at the end of each treatment period - either $8 \mathrm{~g} / \mathrm{d}$ PDX or $8 \mathrm{~g} / \mathrm{d}$ placebo - were compared to samples obtained before the respective treatment, and the results between the two treatment groups were also compared. Average faecal bacterial numbers for the volunteers, as determined by FISH, and expressed as $\log _{10}$ cells/g faeces \pm standard deviations ( $n$ 31) are shown in Table 3. The FISH results for PDX supplementation showed significantly decreased levels of C. histolyticum group from baseline levels $(P<0 \cdot 05)$. PDX treatment was, furthermore, associated with a trend of reduced levels of $C$. histolyticum group $(P=0.0525)$ as compared to the placebo treatment. Both PDX treatment and placebo were found to reduce the levels of lactobacilli/enterococci in relation to their respective baseline values (both $P<0.001)$. In addition, the placebo increased the bacterial numbers within the Eubacterium rectale-C. coccoides group $(P<0.01$, in comparison to baseline); a trend of increased levels for this group was also observed after PDX treatment $(P=0.0593)$. No other significant changes in bacterial population number determined by FISH were observed following the supplementations.

qPCR analyses were conducted to assess the effects of PDX on selected pathogenic and commensal bacterial groups and species (Table 4). Bacterial cell numbers of $C$. bistolyticum 
Table 3. Bacteriology of faecal samples determined by fluorescence in situ hybridisation in the placebo-controlled, double-blind, crossover, human feeding study investigating the effects of polydextrose (PDX; $8 \mathrm{~g} / \mathrm{d}$ ), as compared to the placebo $(8 \mathrm{~g} / \mathrm{d})$, on the human faecal microbiota of a healthy adult population $\ddagger$

(Mean cell numbers $\left(\log _{10}\right)$ and standard deviations, $n 31$ volunteers)

\begin{tabular}{|c|c|c|c|c|c|c|c|c|}
\hline & \multicolumn{4}{|c|}{ PDX } & \multicolumn{4}{|c|}{ Placebo } \\
\hline & \multicolumn{2}{|l|}{ Baseline } & \multicolumn{2}{|c|}{ Treatment } & \multicolumn{2}{|c|}{ Baseline } & \multicolumn{2}{|c|}{ Treatment } \\
\hline & $\begin{array}{c}\text { Mean cell } \\
\text { number }\left(\log _{10}\right)\end{array}$ & SD & $\begin{array}{c}\text { Mean cell } \\
\text { number }\left(\log _{10}\right)\end{array}$ & SD & $\begin{array}{c}\text { Mean cell } \\
\text { number }\left(\log _{10}\right)\end{array}$ & SD & $\begin{array}{c}\text { Mean cell } \\
\text { number }\left(\log _{10}\right)\end{array}$ & SD \\
\hline Total bacteria & $10 \cdot 91$ & 0.42 & $10 \cdot 89$ & 0.30 & $10 \cdot 91$ & 0.27 & $10 \cdot 90$ & 0.27 \\
\hline Atopobium group & 9.74 & 0.39 & $9 \cdot 78$ & 0.42 & $9 \cdot 75$ & 0.25 & $9 \cdot 75$ & 0.37 \\
\hline Bacteroides spp. & $9 \cdot 89$ & 0.42 & $9 \cdot 84$ & 0.36 & 9.92 & 0.33 & 9.98 & 0.38 \\
\hline Bifidobacterium spp. & 9.03 & 0.79 & $9 \cdot 13$ & 0.72 & $9 \cdot 18$ & 0.81 & 8.99 & 0.88 \\
\hline $\begin{array}{l}\text { Eubacterium rectale/Clostridium } \\
\text { coccoides group }\end{array}$ & $10 \cdot 11$ & 0.31 & $10 \cdot 16$ & 0.25 & $10 \cdot 15$ & 0.25 & $10 \cdot 19+\dagger$ & 0.26 \\
\hline Clostridium histolyticum group & $9 \cdot 34$ & 0.36 & $9 \cdot 12 \dagger$ & 0.36 & 9.4 & 0.28 & $9 \cdot 25$ & 0.28 \\
\hline Lactobacillus/Enterococcus spp. & $9 \cdot 18$ & 0.39 & $9 \cdot 16^{\star \star \star}$ & 0.42 & $9 \cdot 25$ & 0.42 & 9.23††† & 0.53 \\
\hline Faecalibacterium prausnitzii & $9 \cdot 77$ & 0.28 & $9 \cdot 7$ & 0.25 & $9 \cdot 81$ & 0.28 & $9 \cdot 74$ & 0.27 \\
\hline
\end{tabular}

${ }^{* \star \star}$ Mean cell numbers were significantly different between PDX and placebo treatments $(P<0.001)$.

Mean cell numbers were significantly different between (PDX baseline $v$. PDX treatment or placebo baseline $v$. placebo treatment): $\uparrow P<0.05$, $\dagger \dagger P<0.01$, $\dagger \dagger \dagger P<0.001$.

$\ddagger$ The aforementioned treatments were consumed in either order, unknown to the investigator and the volunteer.

(clusters I and II) group increased after PDX treatment in comparison to baseline $(P<0 \cdot 01)$ and to placebo $(P<0 \cdot 01)$, which was opposite to the effect measured with FISH. However, the species-specific assay for $C$. perfringens led to no detection within the samples. Faecal counts of $R$. intestinalis were significantly higher after PDX intervention than after the placebo treatment $(P<0.05)$, and similarly, numbers of the C. leptum (cluster IV) were shown to increase with PDX treatment in comparison to baseline values $(P<0 \cdot 001)$, as well as compared to placebo treatment $(P<0 \cdot 001)$. Atopobium numbers remained unchanged following both the PDX and placebo treatments, as measured by both qPCR and FISH.

D. intestinalis was detected in the faecal samples of twenty-one subjects, of which eleven subjects had D. intestinalis in all their samples. PDX treatment did not seem to affect $D$. intestinalis numbers.

$S$. aureus was not detected in faecal samples collected from fourteen volunteers, while it was detected in twelve subjects at only one time point, and in one subject at all time points. S. aureus was detected in five samples at the PDX baseline, in five samples at PDX treatment, and also in five at PDX washout, two subjects had positive samples for all three of their PDX samples (baseline, treatment and washout); thus, no effects were seen due to PDX supplementation. In the placebo group, there were six positive samples at baseline, four after treatment and seven after the washout period.

The C. difficile assay showed only one positive sample, which was in the first washout. Hence, no analyses could be performed on these data.

\section{PCR-denaturing gradient gel electrophoresis and cluster analysis}

In order to ascertain if PDX and/or placebo had an influence on the diversity of faecal microbiota, PCR-DGGE cluster analysis

Table 4. Quantitative PCR results expressed as mean cell numbers $\left(\log _{10}\right)$ and standard deviation per $\mathrm{g}$ faeces

\begin{tabular}{|c|c|c|c|c|c|c|c|c|}
\hline & \multicolumn{4}{|c|}{ Polydextrose } & \multicolumn{4}{|c|}{ Placebo } \\
\hline & \multicolumn{2}{|c|}{ Baseline } & \multicolumn{2}{|c|}{ Treatment } & \multicolumn{2}{|c|}{ Baseline } & \multicolumn{2}{|c|}{ Treatment } \\
\hline & $\begin{array}{c}\text { Mean cell } \\
\text { number }\left(\log _{10}\right)\end{array}$ & SD & $\begin{array}{c}\text { Mean cell } \\
\text { number }\left(\log _{10}\right)\end{array}$ & SD & $\begin{array}{c}\text { Mean cell } \\
\text { number }\left(\log _{10}\right)\end{array}$ & SD & $\begin{array}{c}\text { Mean cell } \\
\text { number }\left(\log _{10}\right)\end{array}$ & SD \\
\hline Atopobium spp. & $8 \cdot 6$ & 0.6 & $9 \cdot 5$ & 0.6 & $8 \cdot 7$ & 0.6 & $9 \cdot 1$ & 0.6 \\
\hline Clostridium difficileł & - & - & - & - & 4.6 & - & - & - \\
\hline Clostridium leptum gp & 8.5 & 0.8 & $9 \cdot 2^{\star \star \star}+† \dagger$ & 0.7 & 8.4 & 0.9 & 8.5 & 0.7 \\
\hline $\begin{array}{l}\text { Clostridium clusters I and II } \\
\text { (histolyticum) }\end{array}$ & $5 \cdot 1$ & 0.7 & $5 \cdot 6^{\star \star}+\dagger$ & 1 & $5 \cdot 3$ & 0.9 & $5 \cdot 1$ & 0.7 \\
\hline Clostridium perfringens & - & - & - & - & - & - & - & - \\
\hline Desulfovibrio intestinalis & $7 \cdot 2$ & 0.9 & $7 \cdot 8$ & 0.8 & 7 & 0.9 & $7 \cdot 4$ & 0.8 \\
\hline Ruminococcus intestinalis & $7 \cdot 8$ & 0.8 & $8 \cdot 2^{*}$ & 0.7 & $7 \cdot 8$ & 0.9 & 7.9 & 0.9 \\
\hline Staphylococcus aureus§ & $5 \cdot 7$ & 0.2 & $6 \cdot 1$ & 0.4 & 5.6 & 0.5 & 5.5 & 0.6 \\
\hline
\end{tabular}

Mean cell numbers were significantly different between PDX and placebo treatments: ${ }^{*} P<0 \cdot 05,{ }^{\star \star} P<0 \cdot 01,{ }^{* \star \star} P<0.001$.

Mean cell numbers were significantly different between treatment and respective baseline values (PDX baseline $v$. PDX treatment or placebo baseline $v$. placebo treatment: $\dagger \uparrow P<0.01, \dagger \dagger \uparrow P<0.001$

$\ddagger$ Data from one subject only.

$\S$ Data from positive samples only. 
Table 5. Diversity index values calculated from denaturing gel gradient electrophoresis profiles during placebo-controlled, double-blind, crossover, human feeding study investigating the effects of polydextrose (PDX; $8 \mathrm{~g} / \mathrm{d})$, as compared to the placebo $(8 \mathrm{~g} / \mathrm{d})$, on the human faecal microbiota of a healthy adult population*

(Mean values and standard deviations, $n 31$ volunteers)

\begin{tabular}{|c|c|c|c|c|c|c|}
\hline & \multicolumn{2}{|c|}{ Simpson's } & \multicolumn{2}{|c|}{$\begin{array}{c}\text { Shannon } \\
\text { Weaver }\left(\log _{10}\right)\end{array}$} & \multicolumn{2}{|c|}{ Fisher's $\alpha$} \\
\hline & Mean & SD & Mean & SD & Mean & SD \\
\hline Baseline & $0.059 \dagger$ & 0.03 & $1.349 \dagger$ & 0.21 & $8.066 \dagger$ & 3.72 \\
\hline PDX & $0.054 \dagger$ & 0.02 & $1.372 \dagger$ & 0.2 & $8 \cdot 191 \dagger$ & 4.11 \\
\hline Placebo & $0.039 \neq \S$ & 0.02 & $1.493 \ddagger \S$ & 0.18 & $10 \cdot 091 \neq \S$ & 4.28 \\
\hline
\end{tabular}

* The aforementioned treatments were consumed in either order, unknown to the investigator and the volunteer.

$\dagger$ Mean values were significantly different from those of placebo $(P<0.05)$.

$\ddagger$ Mean values were significantly different from those of baseline $(P<0.05)$.

$\S$ Mean values were significantly different from those of $\operatorname{PDX}(P<0.05)$.

was conducted. Dendrograms were constructed from DGGE profiles using Dice and unweighted pair-group method using arithmetic average. The values of diversity indices calculated from DGGE profiles are presented in Table 5. The DGGE data indices show that there were significant differences in the indices of the baseline profiles as compared to the placebo treatment $(P=0.008-$ Simpson's index $)$ and the placebo treatment $v$. the PDX treatment ( $P=0.014-$ Simpson's index $)$.

\section{SCFA concentrations}

Table 6 shows the concentrations of faecal SCFA and branched chain fatty acids as determined by GC. No significant changes in faecal concentrations were observed after PDX or placebo treatment.

\section{Analysis of bowel habits and gastrointestinal symptoms}

From volunteer diaries, both the PDX and the placebo products were well tolerated (Table 7). However, less abdominal discomfort (on a scale none, mild, moderate to severe) and pain overall were recorded by the subjects while PDX was consumed (abdominal discomfort, none $P<0.05$ ). There was also a trend for less hard $(P=0.0719)$ and more formed stools $(P<0 \cdot 01)$ during PDX consumption compared to placebo. Additionally, there was a trend for reduced snacking during the PDX period ( $P=0 \cdot 072$; Table 8$)$.

\section{Faecal IgA and $P G E_{2}$ levels}

Following PDX treatment, the level of total faecal IgA was found to be lower (174 (SD 46) $\mu \mathrm{g} / \mathrm{g}$ wet weight faeces) than after the placebo treatment (256 (sD 50) $\mu \mathrm{g} / \mathrm{g}$ wet weight faeces; $P<0 \cdot 05)$. $\mathrm{PGE}_{2}$ was not found to be different after PDX treatment (844 (SD 208) pg/g wet weight faeces) compared to placebo treatment (1116 (SD 315) pg/g wet weight faeces).

\section{Determination of DNA damage by single cell gel electrophoresis (comet assay)}

DNA-damaging potential towards the colonic epithelium exerted by the faecal water was analysed to assess the effect of the PDX and placebo treatment on exposure to genotoxins using the comet assay.

Genotoxicity data showed that the faecal water following PDX treatment led to significantly less genotoxic damage to HT29 DNA as compared to following the placebo treatment $(P<0 \cdot 01)$. No differences were observed compared to baseline values (Fig. 1).

\section{Cyclo-oxygenase gene expression}

Exposure of Caco-2 cells to faecal water collected after PDX treatment induced a 1.80 (SD 0.97)-fold increase in the relative mRNA levels in COX-1 and a 1.32 (SD 52)-fold increase in COX-2 expression in comparison to the reference medium (1.0). Following exposure to faecal water after placebo treatment, COX-1 expression increased 2.22 (SD 1.86)-fold and COX-2 expression increased 1.43 (SD 0.50)-fold. No statistically significant differences were seen between the treatments. Also, the COX-1:COX-2 ratio was not significantly altered between the treatments; 2.54 (SD 5.92) and 2.31 (SD 4.39) after PDX and placebo, respectively.

Table 6. Volatile fatty acid profiles ( $\mathrm{mmol} / \mathrm{g}$ faeces) determined by GC from placebo-controlled, double-blind, crossover, human feeding study investigating the effects of polydextrose (PDX), as compared to the placebo $(8 \mathrm{~g} / \mathrm{d})$, on the human faecal microbiota of a healthy adult population*

(Mean values and standard deviations, $n 31$ volunteers)

\begin{tabular}{|c|c|c|c|c|c|c|c|c|}
\hline & \multicolumn{4}{|c|}{ PDX } & \multicolumn{4}{|c|}{ Placebo } \\
\hline & \multicolumn{2}{|c|}{ Baseline } & \multicolumn{2}{|c|}{ Treatment } & \multicolumn{2}{|c|}{ Baseline } & \multicolumn{2}{|c|}{ Treatment } \\
\hline & Mean & SD & Mean & SD & Mean & SD & Mean & SD \\
\hline Acetic acid & $29 \cdot 5$ & $14 \cdot 6$ & 23.9 & $15 \cdot 3$ & $25 \cdot 6$ & $14 \cdot 4$ & $24 \cdot 7$ & 14.7 \\
\hline Propionic acid & $10 \cdot 1$ & 4.4 & 8.9 & $5 \cdot 2$ & $9 \cdot 4$ & $4 \cdot 8$ & $9 \cdot 8$ & $5 \cdot 3$ \\
\hline Iso-butyric acid & $1 \cdot 2$ & 0.8 & 0.9 & 0.4 & 1.0 & 0.5 & $1 \cdot 1$ & 0.4 \\
\hline$n$-Butyric acid & $9 \cdot 3$ & $7 \cdot 1$ & 6.5 & $5 \cdot 2$ & 6.5 & $4 \cdot 7$ & 6.5 & $5 \cdot 8$ \\
\hline Iso-valeric acid & $1 \cdot 7$ & 1.4 & $1 \cdot 3$ & 0.6 & 1.4 & 0.7 & 1.5 & 0.7 \\
\hline n-Caproid acid & $1 \cdot 0$ & 0.9 & 0.9 & $1 \cdot 0$ & 0.9 & $1 \cdot 0$ & 0.5 & 0.4 \\
\hline
\end{tabular}

* The aforementioned treatments were consumed in either order, unknown to the investigator and the volunteer. 
Table 7. Volunteer response diary data; changes in volunteer responses during the feeding study

(Mean values and standard deviations)

\begin{tabular}{|c|c|c|c|c|c|c|c|c|c|c|c|c|c|c|c|c|}
\hline & \multirow[b]{3}{*}{$\begin{array}{l}\text { Stools/d } \\
\text { number }\end{array}$} & \multicolumn{15}{|c|}{ Percentage of occurrence } \\
\hline & & \multicolumn{3}{|c|}{ Consistency } & \multicolumn{4}{|c|}{ Abdominal discomfort } & \multicolumn{4}{|c|}{ Bloating } & \multicolumn{4}{|c|}{ Flatulence } \\
\hline & & Hard & Formed & Soft & None & Mild & Moderate & Severe & None & Mild & Moderate & Severe & None & Mild & Moderate & Severe \\
\hline \multicolumn{17}{|l|}{ Placebo } \\
\hline Mean & 1.5 & $12 \cdot 7$ & $57 \cdot 2$ & 30.1 & 70.4 & 21.4 & 6.6 & 1.7 & $68 \cdot 8$ & $23 \cdot 6$ & 6.5 & $1 \cdot 2$ & 45 & $36 \cdot 4$ & 14.7 & 3.8 \\
\hline SD & 0.4 & 19.5 & 21.5 & $22 \cdot 3$ & 30.8 & $23 \cdot 0$ & 14.9 & $6 \cdot 2$ & 34.5 & $26 \cdot 7$ & $13 \cdot 0$ & $5 \cdot 0$ & 33.9 & $26 \cdot 9$ & $19 \cdot 4$ & 8.0 \\
\hline \multicolumn{17}{|l|}{ PDX } \\
\hline Mean & 1.3 & $7 \cdot 8$ & $69 \cdot 7^{\star \star}$ & 22.5 & $83 \cdot 5^{\star}$ & $13 \cdot 4$ & 2.5 & 0.5 & $76 \cdot 4$ & $17 \cdot 3$ & 4.9 & 1.3 & 40.9 & $43 \cdot 7$ & 11.7 & 3.8 \\
\hline SD & 0.4 & $12 \cdot 4$ & 23.0 & $19 \cdot 3$ & 23.9 & $17 \cdot 8$ & $8 \cdot 7$ & $2 \cdot 8$ & $23 \cdot 6$ & $18 \cdot 2$ & $10 \cdot 3$ & 4.2 & $32 \cdot 0$ & $26 \cdot 0$ & 14.9 & 7.6 \\
\hline
\end{tabular}

PDX, polydextrose.

Mean values were significantly different between PDX and placebo treatments: ${ }^{\star} P<0.05,{ }^{\star \star} P<0.01$

\section{Faecal polydextrose}

Faecal PDX excretion was found to be significantly higher after the PDX treatment compared to the placebo treatment and baseline values ( 8.05 (SD 4.47) v. 0.25 (SD 0.96) v. 0.05 (sD0.23) $\mathrm{g} / \mathrm{kg}$ faeces, respectively; $P<0.0001$ ).

\section{Discussion}

To date, few studies have been conducted investigating the prebiotic effects of PDX in human intervention studies. The present crossover study aimed to assess the effects of such supplementation in a European-based population.

Increased faecal PDX concentrations were detected after PDX intervention, thus demonstrating that PDX was not completely fermented by the colonic microbes and some PDX reached the distal part of the large intestine. Assuming a faecal output of approximately $100 \mathrm{~g}^{(22)}, 0 \cdot 8 \mathrm{~g}$ (or $10 \%$ ) of the consumed PDX ( $8 \mathrm{~g})$ was excreted in the faeces. A slow but constant fermentation of PDX has been demonstrated previously $^{(35,36)}$, and this feature could provide benefits for the health of the distal colon, as a substrate for the saccharolytic type fermentation is constantly available. Increased proteolytic fermentation in the distal part of the colon can contribute towards an increased risk of genotoxicity ${ }^{(35)}$; thus, increasing saccharolytic fermentation at the expense of proteolytic microbial metabolism should therefore benefit the health of the colon ${ }^{(37)}$.

Decreased genotoxic effects of the faecal water on colonocytes after PDX consumption were demonstrated in this trial. The induction of DNA damage and mutations, brought about by a range of environmental (dietary) genotoxins, are key factors in the early stages of carcinogenesis initiation. Thus, this study provides evidence that PDX may aid in the reduction of such genotoxic events. The cytotoxic effects of faecal water are considered to reflect the ability of these genotoxins to damage the colonic epithelium, resulting in a hyperproliferative response characteristic of early stages of tumour promotion in the colon ${ }^{(38)}$. The $C O X-1$ gene is expressed constitutively in the gastrointestinal tract, whereas the $C O X-2$ gene is over-expressed in conditions such as gastrointestinal inflammation and cancerous diseases ${ }^{(39)}$. No effects of the PDX faecal water on $C O X$ gene expression in Caco-2 colon cancer cells were demonstrated.

Analysis of selected members of the intestinal microbiota during this double-blind, placebo-controlled, randomised crossover study demonstrated that PDX fermentation leads to modulations of the colonic microbiota. Decreased numbers of faecal C. histolyticum (clusters I and II) and lactobacilli/ enterococci were measured with FISH, but the levels of Bifidobacterium, Bacteroides and Atopobium genera remained unchanged. According to qPCR analysis, however, PDX increased numbers of the Clostridium clusters I, II and IV and $R$. intestinalis. C. leptum cluster IV and E. rectale-C. coccoides group which includes important butyrate-producing microbes, such as Faecalibacterium prausnitzii and $R$. intestinalis, and faecal levels of these microbes have been correlated to faecal butyrate concentrations ${ }^{(38,40)}$. However, in the present study, no concomitant change in faecal butyrate levels, or in any other SCFA, was observed. The major part of research on prebiotic effects has, to date, mostly focused on the bifidogenic (and lactobacilli-increasing) properties of the candidate products, whereas in the future it may be worth investigating the impact of dietary intervention

Table 8. Volunteer response diary data; changes in volunteer responses during the feeding study*

(Mean values and standard deviations)

\begin{tabular}{|c|c|c|c|c|c|c|c|c|c|c|c|c|c|c|c|c|c|c|}
\hline & \multicolumn{2}{|c|}{ Hungry } & \multicolumn{2}{|c|}{ Full } & \multicolumn{2}{|c|}{$\begin{array}{c}\text { Desire to } \\
\text { eat }\end{array}$} & \multicolumn{2}{|c|}{$\begin{array}{l}\text { Snack } \\
\text { appetite }\end{array}$} & \multicolumn{2}{|c|}{ Contented } & \multicolumn{2}{|c|}{ Irritability } & \multicolumn{2}{|c|}{ Sleepy } & \multicolumn{2}{|c|}{ Alert } & \multicolumn{2}{|c|}{$\begin{array}{c}\text { Ability to } \\
\text { concentrate }\end{array}$} \\
\hline & Mean & SD & Mean & SD & Mean & SD & Mean & SD & Mean & SD & Mean & SD & Mean & SD & Mean & SD & Mean & SD \\
\hline Placebo & $4 \cdot 75$ & 2.98 & $4 \cdot 67$ & 2.50 & $4 \cdot 71$ & $3 \cdot 18$ & $5 \cdot 17$ & 3.40 & 6.58 & $1 \cdot 71$ & $3 \cdot 13$ & $2 \cdot 72$ & $4 \cdot 17$ & $2 \cdot 76$ & $6 \cdot 29$ & $2 \cdot 39$ & $6 \cdot 54$ & $2 \cdot 40$ \\
\hline Polydextrose & 4.09 & $2 \cdot 57$ & $5 \cdot 17$ & $2 \cdot 72$ & $3 \cdot 71$ & $2 \cdot 58$ & 3.57 & 2.59 & $6 \cdot 73$ & $2 \cdot 12$ & $2 \cdot 43$ & $2 \cdot 02$ & 3.39 & $2 \cdot 78$ & $5 \cdot 65$ & $2 \cdot 81$ & $6 \cdot 43$ & $2 \cdot 39$ \\
\hline
\end{tabular}

${ }^{*}$ On a scale from 0 to 10 ; 0 being not at all; 10 being very. 


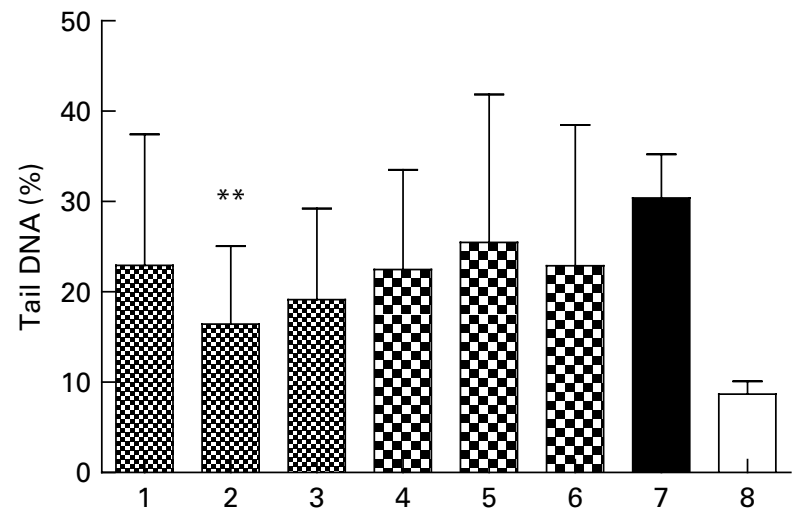

Fig. 1. Changes in faecal water genotoxicity, as determined by DNA tail length following the comet assay. Values are means and standard deviations represented by vertical bars, $n 11$ volunteers. (1) Pre-polydextrose (PDX) treatment; (2) PDX treatment; (3) post-PDX washout; (4) pre-placebo treatment; (5) placebo treatment; (6) post-placebo washout; (7) positive control $\mathrm{H}_{2} \mathrm{O}_{2} ;(8)$ negative control - PBS. ${ }^{\star \star}$ Mean values were significantly different to placebo treatment $(P<0.01)$.

on other genera, such as Roseburia, Feacalibacterium and Eubacterium ${ }^{\text {(7) }}$

Sulphide, produced by sulphate-reducing bacteria, is toxic to colonic epithelial cells, and may counteract the beneficial effects of butyrate ${ }^{(41)}$. D. intestinalis, a sulphate-reducing bacterium, was not affected by PDX consumption; neither were the levels of potentially pathogenic organisms such as C. difficile, $C$. perfringens and $S$. aureus. These microbes were mostly not detected or detected only in part of the samples, indicating that they are either not present or present at such low concentrations that they are below the detection limits of the qPCR assays

Decreasing numbers of the C. bistolyticum (clusters I and II) upon PDX treatment were detected by FISH; however, the same clusters were significantly increased according to qPCR analysis. This contradiction in results obtained with different methods has also been reported in previous studies ${ }^{(42,43)}$. The difference could be due to variability in rRNA operon copy numbers in species covered by the probe; hence, amplification in PCR will be influenced by this variation. Changes in bacterial levels within the group may affect the number outcome differently; for example, it is known that $C$. bistolyticum possesses 10 rRNA copies ${ }^{(44)}$, whereas $C$. beijerinckii possesses thirteen copies - both species are targeted by primers for the Clostridium I and II qPCR assay. Thus, with the present probe, the FISH analysis may be more accurate. C. perfringens was not detected in the samples (analysed by speciesspecific qPCR), indicating that PDX treatment does not effectively increase this potentially pathogenic microbe to detectable numbers but instead increases other members of the Clostridium clusters I and II, therefore demonstrating an encouraging outcome of PDX treatment.

Comparison of the microbial changes observed in this study to the previously published study of Jie et $a l .{ }^{(15)}$ has shown some differences in the effects; they observed that PDX led to dose-dependent increases in bifidobacteria and lactobacilli and decreased three Bacteroides species. However, it should be considered that the research of Jie et al. was performed in a parallel study design and used the less quantifiably accurate plating techniques. In the present study, the numbers of Bifidobacterium and Bacteroides remained unchanged, while those of Lactobacillus-Enterococcus decreased. This reduction was modest, but statistically significant. The biological relevance, however, would need to be determined. These differences could derive from the variation of responses between the two different study populations (Chinese $v$. European), and the different methods used in enumeration of the microbes. An inverse correlation between the initial levels of bifidobacteria and the magnitude of prebiotic bifidogenicity has been demonstrated for some prebiotic substrates, such as fructo-oligosaccharides ${ }^{(45)}$ and galacto-oligosaccharides ${ }^{(28)}$, where high initial levels of bifidobacteria tended to remain unchanged after prebiotic intervention. In this study, the baseline levels of bifidobacteria, as measured using FISHtechnique, were above $\log _{10} 9 \cdot 0$ cells/g and no effects on bifidobacteria were seen.

Previously, fermentation of PDX by colonic bacteria has been shown to increase the production of SCFA in in vitro models $^{(13,36)}$, in rats ${ }^{(20)}$, pigs ${ }^{(19)}$ and in human subjects ${ }^{(15)}$ In particular, the levels of butyrate and acetate have been highly elevated in the previous studies due to PDX fermentation. Such changes were, however, not observed in the present study.

Faecal immune markers IgA and $\mathrm{PGE}_{2}^{(46)}$ were also measured and decreased levels of IgA were demonstrated after PDX consumption. In previous studies, increases in the intestinal immune parameters such as IgA and $\mathrm{PGE}_{2}$ levels have been measured after prebiotic and probiotic consumption $^{(46)}$, but also unchanged ${ }^{(26,47)}$ and decreased levels have been reported $^{(26)}$. It has been reported that many factors including stress and exercise can impact IgA levels; therefore discrepancies in changes may be a result of this.

In the present study, the placebo, maltodextrin, was seen to have an effect on the diversity of the faecal microbiota, leading to increased diversity - the same effect was not observed for PDX. The increase in diversity was relatively small. Little information is available on increased microbial diversity; however, the research of Scanlan et al. ${ }^{(44)}$ associated increased diversity with colonic polyps and cancer formation. However, the absence of a change in genotoxicity in this incidence was not the case. Further knowledge of the bacterial groups involved in this increased diversity would help to clarify these findings.

The effects of PDX consumption on the quality of life and bowel habits of the subjects were also assessed during the feeding trial. PDX did not influence the measured aspects of quality of life (hunger, motivation, mood and mental alertness), although a trend towards reduced snacking was observed. This agrees with previous findings in another human feeding study, where PDX was shown to increase postprandial satiety ${ }^{(48)}$. However, the effects on bowel habits were more profound, as less abdominal discomfort (none on a scale none, mild, moderate, severe) was recorded by the subjects while the PDX was consumed. There was also a trend towards less hard and more formed stools during PDX consumption. 
Previously, an in vitro study showed that PDX fermentation led to less gas production compared to the prebiotics tested (fructo-oligosaccharides, galacto-oligosaccharides and inulin) ${ }^{(49)}$. Furthermore, the members of Clostridium cluster IV are Ruminococcus, Eubacterium and Faecalibacterium that are butyrate-producing commensals of which, in particular the latter has been suggested to be beneficial. Minimal gas production may explain the sensation of less abdominal pain by subjects during the feeding trial. Improved stool consistency (together with shortened oro-faecal transit time) has also been previously demonstrated in constipated subjects ${ }^{(22)}$, and indicates the fibre-like properties of PDX.

PDX led to a significant decline in faecal water genotoxicity of volunteers following consumption. This shows the potential of PDX for reducing the risk factors that may be associated with colorectal cancer. This change coincides with increases in the numbers of a bacterial population that includes known butyrate producers. However, further investigation would be required to determine the activities of genes involved in the butyrate formation ${ }^{(50)}$.

\section{Acknowledgements}

Brita Mäki and Jaana Larsson-Leskelä, Danisco Health and Nutrition, are thanked for their skilful technical assistance in the analysis of the faecal samples. Dr Janne Nikkilä Esa Alhoniemi are acknowledged for conducting the statistical analyses. This work was funded by Danisco, who are marketing polydextrose. The authors (H. R., S. D. F., K. O., J. K., A. C. O.) were employees of Danisco at the time of the study. A. C. O., I. R. R., R. A. R. and G. R. G. designed the study; F. F. was responsible for organising the study and conducting the FISH and SCFA analyses; S. D. F. and K. O. performed the Caco-2 cell experiments; A. C. and G. E. W. performed the DGGE analysis, the faecal-water comet assay and the volunteer diary analysis; J. K. did the qPCR analysis; F. F. and H. R. interpreted the results; F. F., A. C., G. E. W., A. C. O., H. R., S. F., K. O. and G. R. G. were all involved with writing the manuscript. For A. C., F. F., I. R. R., R. A. R., G. R. G. and G. E. W., there were no conflicts of interest.

\section{References}

1. O'Flaherty S, Saulnier DM, Pot B, et al. (2010) How can probiotics and prebiotics impact mucosal immunity? Gut Microbes 1, 293-300.

2. Ewaschuk JB, Diaz H, Meddings L, et al. (2008) Secreted bioactive factors from Bifidobacterium infantis enhance epithelial cell barrier function. Am J Physiol Gastrointest Liver Physiol 295, G1025-G1034.

3. Coakley M, Johnson MC, McGrath E, et al. (2006) Intestinal bifidobacteria that produce trans-9, trans-11 conjugated linoleic acid: a fatty acid with antiproliferative activity against human colon SW480 and HT-29 cancer cells. Nutr Cancer 56, 95-102.

4. Rafter J, Bennett M, Caderni G, et al. (2007) Dietary synbiotics reduce cancer risk factors in polypectomized and colon cancer patients. Am J Clin Nutr 85, 488-496.

5. Gibson GR, Scott KP, Rastall RA, et al. (2010) Dietary prebiotics: current status and new definition. IFIS Bull 7, 1-19.
6. Costabile A, Kolida S, Klinder A, et al. (2010) A double-blind, placebo-controlled, cross-over study to establish the bifidogenic effect of a very-long-chain inulin extracted from globe artichoke (Cynara scolymus) in healthy human subjects. Br J Nutr 104, 1007-1017.

7. Roberfroid M, Gibson GR, Hoyles L, et al. (2010) Prebiotic effects: metabolic and health benefits. Br J Nutr 104, Suppl. 2, S1-S63.

8. Divisi D, Di Tommaso S, Salvemini S, et al. (2006) Diet and cancer. Acta Biomed 77, 118-123.

9. Rowland IR, Mallett AK \& Wise A (1985) The effect of diet on the mammalian gut flora and its metabolic activities. Crit Rev Toxicol 1, 31-103.

10. Hamer HM, Jonkers D, Venema K, et al. (2008) Review Article: the role of butyrate on colonic function. Aliment Pharmacol Ther 27, 104-119.

11. Johnson SK, Chua V, Hall RS, et al. (2006) Lupin kernel fibre foods improve bowel function and beneficially modify some putative faecal risk factors for colon cancer in men. BrJ Nutr 95, 372-378.

12. Craig SA, Holden JF, Khaled MY, et al. (2000) Determination of polydextrose as dietary fiber in foods. J AOAC Int $\mathbf{8 3}$, 1006-1012.

13. Mäkivuokko H, Kettunen H, Saarinen M, et al. (2007) The effect of cocoa and polydextrose on bacterial fermentation in gastrointestinal tract simulations. Biosci Biotechnol Biochem 71, 1834-1843.

14. Probert HM, Apajalahti JH, Rautonen N, et al. (2004) Polydextrose, lactitol, and fructo-oligosaccharide fermentation by colonic bacteria in a three-stage continuous culture system. Appl Environ Microbiol 70, 4505-4511.

15. Jie Z, Bang-Yao L, Ming-Jie X, et al. (2000) Studies on the effects of polydextrose intake on physiologic functions in Chinese people. Am J Clin Nutr 72, 1503-1509.

16. Mohan R, Koebnick C, Schildt J, et al. (2006) Effects of Bifidobacterium lactis Bb12 Supplementation on intestinal microbiota of preterm infants: a double-blind, placebocontrolled, randomized study. JClin Microbiol 44, 4025-4031.

17. Wallace JL \& Devchand PR (2005) Emerging roles for cyclooxygenase- 2 in gastrointestinal mucosal defense. $\mathrm{Br} J$ Pharmacol 145, 275-282.

18. Mäkivuokko H, Nurmi J, Nurminen P, et al. (2005) In vitro effects on polydextrose by colonic bacteria and caco- 2 cell cyclooxygenase gene expression. Nutr Cancer 52, 94-104.

19. Fava F, Mäkivuokko H, Siljander-Rasi H, et al. (2007) Effect of polydextrose on intestinal microbes and immune functions in pigs. BrJ Nutr 98, 123-133.

20. Peuranen S, Tiihonen K, Apajalahti J, et al. (2004) Combination of polydextrose and lactitol affects microbial ecosystem and immune responses in rat gastrointestinal tract. Br J Nutr 91, 905-914.

21. Wasson GR, McKelvey-Martin VJ \& Downes CS (2008) The use of the comet assay in the study of human nutrition and cancer. Mutagenesis 23, 153-162.

22. Hengst C, Ptok S, Roessler A, et al. (2009) Effects of polydextrose supplementation on different faecal parameters in healthy volunteers. Int J Food Sci Nutr 60, Suppl. 5, 96-105.

23. Muyzer G, de Waal EC \& Uitterlinden AG (1993) Profiling of complex microbial populations by denaturing gradient gel electrophoresis analysis of polymerase chain reactionamplified genes coding for $16 \mathrm{~S}$ rRNA. Appl Environ Microbiol 59, 695-700.

24. Martin-Pelaez S, Costabile A, Hoyles L, et al. (2010) Evaluation of the inclusion of a mixture of organic acids or lactulose into the feed of pigs experimentally challenged with Salmonella typhimurium. Vet Microbiol 142, 337-345. 
25. Rinttilä T, Kassinen A, Malinen E, et al. (2004) Development of an extensive set of $16 \mathrm{~S}$ rDNA-targeted primers for quantification of pathogenic and indigenous bacteria in faecal samples by real-time PCR. J Appl Microbiol 97, 1166-1177.

26. Lahtinen SJ, Forssten S, Aakko J, et al. (2011) Probiotic cheese containing Lactobacillus rbamnosus HN001 and Lactobacillus acidophilus NCFM ${ }^{\circledR}$ modifies subpopulations of fecal lactobacilli and Clostridium difficile in the elderly. Age (Epublication ahead of print version 25 January 2011).

27. Matsuki T, Watanabe K, Fujimoto J, et al. (2004) Use of $16 \mathrm{~S}$ rRNA gene-targeted group-specific primers for real-time PCR analysis of predominant bacteria in human feces. Appl Environ Microbiol 70, 7220-7228.

28. Tiihonen K, Suomalainen T, Tynkkynen S, et al. (2008) Effect of prebiotic supplementation on a probiotic bacteria mixture: comparison between a rat model and clinical trials. Br J Nutr 99, 826-831.

29. Mäkivuokko H, Forssten S, Saarinen M, et al. (2010) Synbiotic effects of lactitol and Lactobacillus acidophilus NCFM in a semi-continuous colon fermentation model. Benef Microbes 1, 131-137.

30. Brakstad OG, Aasbakk K \& Maeland JA (1992) Detection of Staphylococcus aureus by polymerase chain reaction amplification of the nuc gene. J Clin Microbiol 30, 1654-1660.

31. Zhao G, Nyman M \& Jönsson ÅJ (2005) Rapid determination of short-chain fatty acids in colonic contents and faeces of humans and rats by acidified water-extraction and directinjection gas chromatography. Biomed Chromatogr 20, 674-682.

32. Walton GE, Rastall RA, Martini M, et al. (2010) A doubleblind, placebo controlled human study investigating the effects of coffee derived manno-oligosaccharides on the faecal microbiota of a healthy adult population. Int $J$ Probiotics Prebiotics 5, 75-84.

33. Kumaravel TS, Vilhar B, Faux SP, et al. (2009) Comet assay measurements: a perspective. Cell Biol Toxicol 25, 53-64.

34. Livak KJ \& Schmittgen TD (2001) Analysis of relative gene expression data using real-time quantitative PCR and the 2(-Delta Delta C(T)) method. Methods 25, 402-408.

35. Lahtinen SJ, Knoblock K, Drakoularakou A, et al. (2010) Effect of molecule branching and glycosidic linkage on the degradation of polydextrose by gut microbiota. Biosci Biotechnol Biochem 74, 2016-2021.

36. Mäkeläinen H, Mäkivuokko H, Salminen S, et al. (2007) The effects of polydextrose and xylitol on microbial community and activity in a 4-stage colon simulator. J Food Sci $\mathbf{7 2}$, 153-159.

37. Le Leu RK, Brown IL, Hu Y, et al. (2007) Effect of dietary resistant starch and protein on colonic fermentation and intestinal tumourigenesis in rats. Carcinogenesis $\mathbf{2 8}$, $240-245$.
38. Rafter JJ, Child P, Anderson AM, et al. (1987) Cellular toxicity of fecal water depends on diet. Am J Clin Nutr 45, 559-563.

39. Nurmi JT, Puolakkainen PA \& Rautonen NE (2005) Bifidobacterium lactis sp. 420 up-regulates cyclooxygenase (Cox)-1 and down-regulates Cox-2 gene expression in a Caco-2 cell culture model. Nutr Cancer 51, 83-92.

40. Hughes R, Magee EA \& Bingham S (2000) Protein degradation in the large intestine: relevance to colorectal cancer. Curr Issues Intest Microbiol 1, 51-58.

41. Fite A, Macfarlane GT, Cummings JH, et al. (2004) Identification and quantitation of mucosal and faecal desulfovibrios using real time polymerase chain reaction. Gut 53, 523-529.

42. Lahtinen SJ, Gueimonde M, Ouwehand AC, et al. (2006) Comparison of four methods to enumerate probiotic bifidobacteria in a fermented food product. Food Microbiol 23, 571-577

43. Noble RT, Blackwood AD, Griffith JF, et al. (2010) Comparison of rapid quantitative PCR-based and conventional culture-based methods for enumeration of Enterococcus spp. and Escherichia coli in recreational waters. Appl Environ Microbiol 76, 7437-7443.

44. Scanlan PD, Shanahan F, Clune Y, et al. (2008) Cultureindependent analysis of the gut microbiota in colorectal cancer and polyposis. Environ Microbiol 10, 789-798.

45. Tuohy KM, Kolida S, Lustenberger AM, et al. (2001) The prebiotic effects of biscuits containing partially hydrolysed guar gum and fructo-oligosaccharides - a human volunteer study. Br J Nutr 86, 341-348

46. Ouwehand AC, Tiihonen K, Saarinen M, et al. (2009) Influence of a combination of Lactobacillus acidophilus NCFM and lactitol on healthy elderly: intestinal and immune parameters. BrJ Nutr 101, 367-375.

47. Hafer A, Krämer S, Duncker S, et al. (2007) Effects of oral lactulose on clinical and immunohistochemical parameters in patients with inflammatory bowel disease: a pilot study. BMC Gastroenterol 7, 36.

48. King NA, Craig SA, Pepper T, et al. (2005) Evaluation of the independent and combined effects of xylitol and polydextrose consumed as a snack on hunger and energy intake over 10 d. Br J Nutr 93, 911-915.

49. Hernot DC, Boileau TW, Bauer LL, et al. (2009) In vitro fermentation profiles, gas production rates, and microbiota modulation as affected by certain fructans, galactooligosaccharides, and polydextrose. J Agric Food Chem 57, $1354-1361$

50. Louis P, Young P, Holtrop G, et al. (2010) Diversity of human colonic butyrate-producing bacteria revealed by analysis of the butyryl-CoA:acetate CoA-transferase gene. Environ Microbiol 12, 304-314. 